\title{
La escritura de Dios: A propósito del Reverendo George Reinke Heath, autor del 'Glosario miskito con comentarios etnográficos'
}

\author{
Danilo Salamanca \\ "Asociación Centroamericana de Lingüística (ACALING)"
}

El trabajo que estamos presentando a continuación traducido al español fue publicado originalmente en inglés como un artículo del volumen 16 de la revista académica International Journal of American Linguistics en el año de 1950.

Al inicio del artículo que estamos publicando se señala que se trata de un extracto de una descripción lexicográfica más amplia: 510 páginas manuscritas completadas en 1947. Es seguramente a partir de ese manuscrito que fue elaborado el excelente Diccionario MiskitoEspañol, Español Miskito, publicado por primera vez en 1961 (Tegucigalpa: Imprenta Calderon) bajo la autoría conjunta de Heath y el también misionero W.G. Marx. Desde entonces ese trabajo clásico, que ha influenciado profundamente todo lo que se ha hecho posteriormente en ese campo, ha sido reimpreso numerosas veces.

Heath, que había muerto en 1956 pasó la mayor parte de su vida adulta entre los miskitos y debía ser un hablante competente de la lengua: es autor también de una finísima gramática del miskito ('Grammar of the miskito language'. F Lindenbein, Herrnhut (1927)).

Es probable que, además de la adaptación al español del manuscrito miskito-inglés que Heath había elaborado, Marx haya contribuido en la parte Español-Miskito del diccionario, al igual que la introducción. En ella se señala la voluntad de contribuir con esa publicación en cuanto a facilitar a los hablantes del miskito la interacción con los hondureños de habla española. Es probablemente por esa motivación práctica, no académica, de la publicación, que no todos los términos del glosario que publicamos aquí aparecen en el diccio-

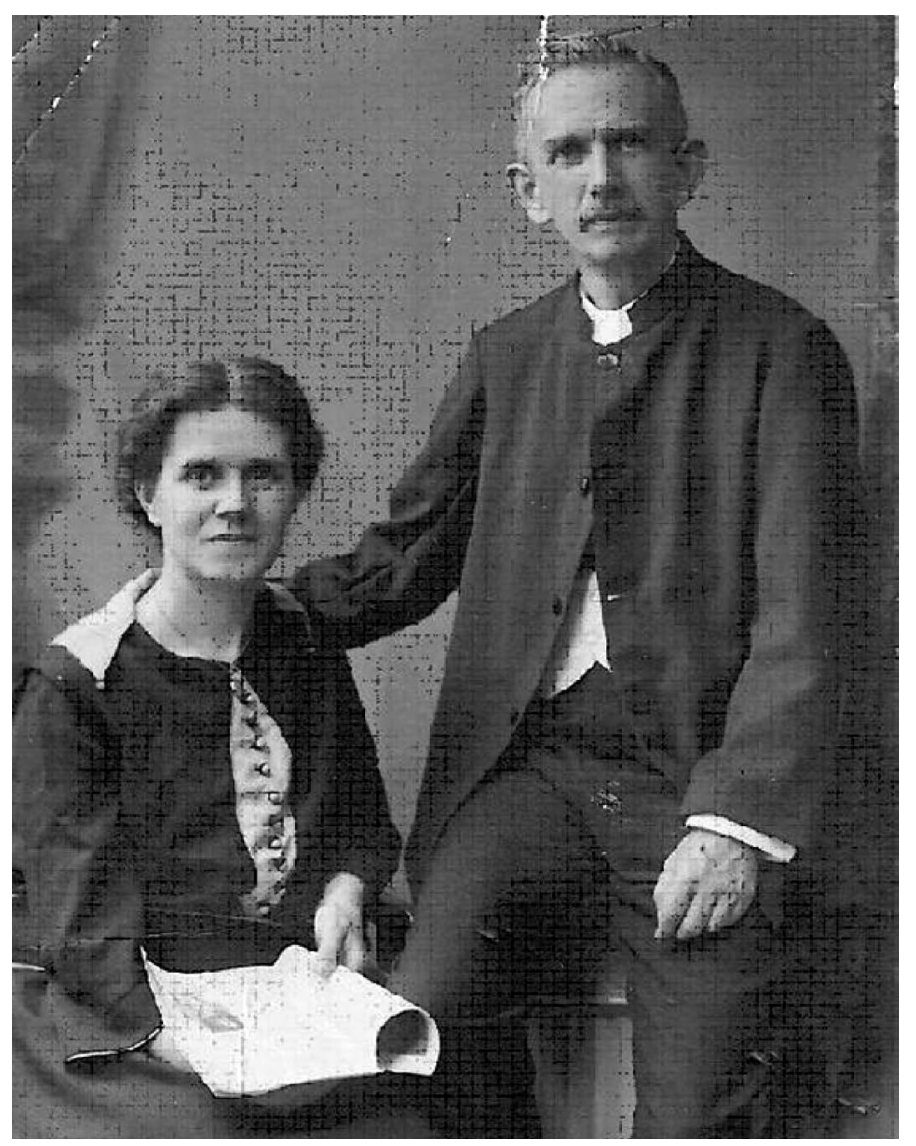

El misionero George Reinke Heath y su esposa Margarita de Heath

nario de Heath y Marx. Muchos están presentes pero en general la información etnográfica es bastante más reducida.

Tanto las lenguas como las tradiciones culturales de nuestros pueblos originarios tienden a erosionarse conforme los avances tecnológicos y la interconectividad producen una cultura cada vez más planetaria y uniforme. La publicación en español de este glosario de tér- 
minos culturalmente significativos de Heath puede ser vista entonces como un suplemento a la obra clásica de Heath y Marx. Aquella ha sido ya durante más de medio siglo un precioso instrumento para todos los que han querido acercarse a la lengua y cultura miskita. El glosario que aquí publicamos nos da acceso a un tesoro, más íntimo, de creencias, conocimientos y tradiciones antiguas que incluso los propios miskitos podrían llegar a olvidar.
Heath es sin ninguna duda la persona que más ha contribuido a los estudios de la lengua miskita. Su obra, una gramática, un diccionario y como consecuencia un sistema de escritura para el idioma, es la culminación del trabajo que los moravos hicieron para poder publicar sus textos religiosos en miskito. Desde su fervorosa perspectiva se podría decir que Heath invirtió su vida en crear las condiciones para que Dios pudiera expresarse correctamente por escrito en miskito. Cabe suponer que su trabajo, minimalista y preciso, le habría merecido por lo menos el cielo.

\section{Reseña biográfica}

El misionero moravo, George Reinke Heath nació en Jamaica en 1879 y murió en 1956. Su padre inglés era también misionero moravo y se desempeñó a lo largo de las Antillas. Fue escolarizado en la muy estricta escuela morava de Fulnek, en Inglaterra. Estudió después en el seminario teológico de Betlehem, de donde se graduó, al igual que su padre George Octavius antes y su hermano menor Edwin después.

De acuerdo a declaraciones de su sobrina Marion Graham Heath, recogidas en Octubre del 2006 y publicadas en Internet, George junior era considerado en su familia como un genio: hablaba 12 idiomas, entre ellos el español, con un terrible acento inglés, pero también sabía Latín, Hebreo, Griego, Arameo, Alemán, Francés, Etc. Etc. Es el autor de los excelentes 'Grammar of the miskito language' (1927) y 'Diccionario miskito-español, español miskito', el segundo editado y publicado póstumamente -1961- por el también misionero y médico W.G,Marx en la imprenta Calderón de Tegucigalpa. Estos dos libros han sido fundamentales para el desarrollo de los estudios del miskito.

Junto con su esposa Marguerite, nacida el mismo año que él y muerta en 1964, George Reinke Heath dedicó la mayor parte de su vida al trabajo misionero en la Mosquitia nicaragüense y hondureña. La pareja no tuvo hijos.

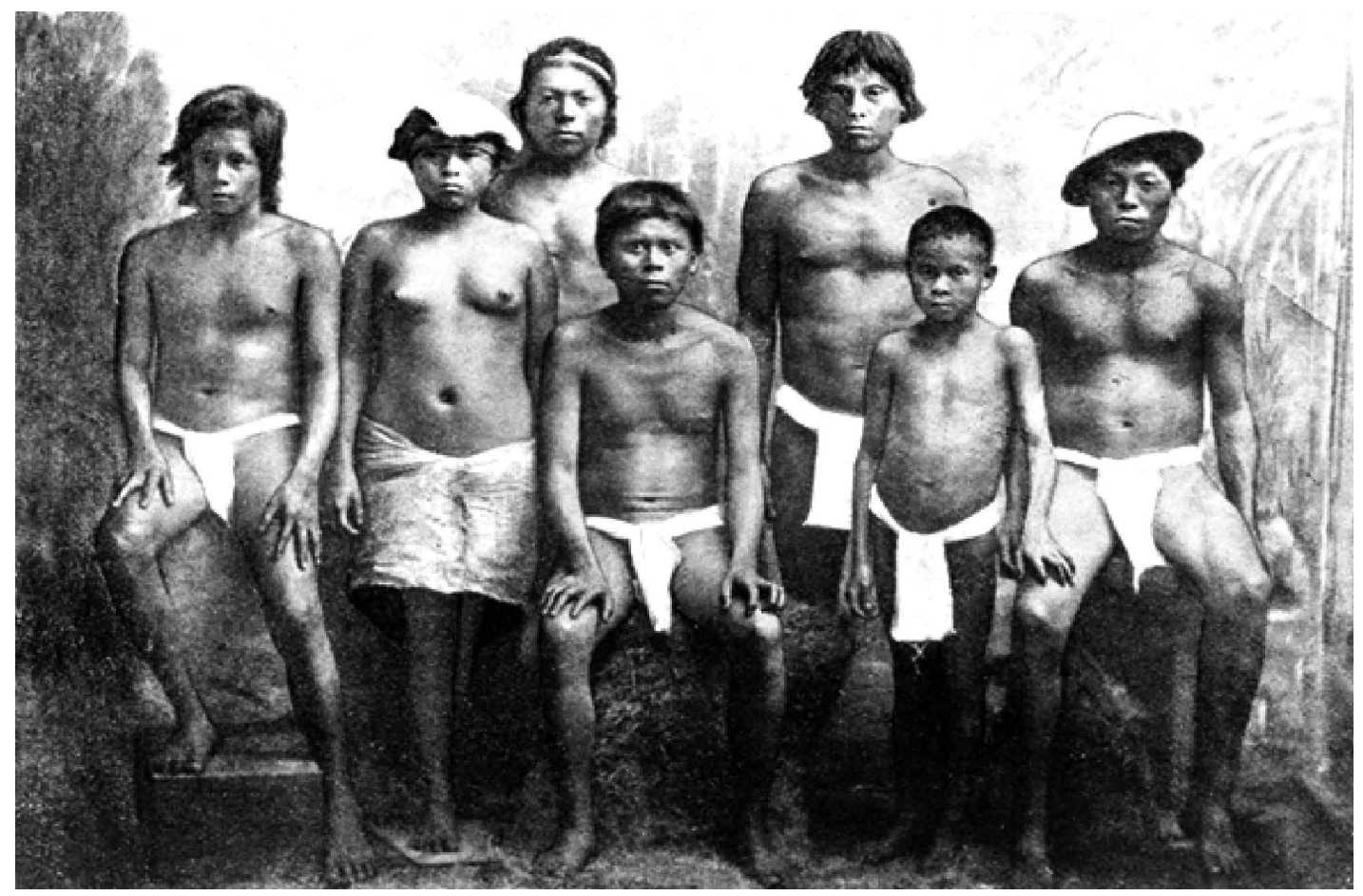

Misioneros moravos de la Mosquitia en Nicaragua (archivo Wani). 